\section{Research Article}

Accepted: 11-02-2021

To Cite: Zarifikhosroshahi M, Ergun Z, 2021. The effect of storage temperature on the composition of fatty acids in Crimson Sweet (Citrullus lanatus var. lanatus) watermelon Cultivar seeds. Journal of the Institute of Science and Technology, 11(2): $839-845$.

\title{
The Effect of Storage Temperature on the Composition of Fatty Acids in Crimson Sweet (Citrullus lanatus var. lanatus) Watermelon Cultivar Seeds
}

\section{Mozhgan ZARIFIKHOSROSHAHI ${ }^{*}$, Zeynep ERGUN ${ }^{2}$}

\begin{abstract}
Crimson Sweet is one of the favorite watermelon cultivars with high sugar content and great flavor containing small and dark seeds. Both fruit flesh and seeds have high nutrition content. In order to evaluate new sources of oil for the growing population, watermelon seed oil is used in some nations. Therefore, it was aimed to determine the fatty acid profile of differentially stored Crimson Sweet watermelon seed oil in this study. The results indicated that seeds are rich in Omega 6 fatty acid (40.62-42.34\%). The amount of this essential fatty acid was higher at samples stored at $4^{\circ} \mathrm{C}$. Palmitic, oleic, and stearic acids are the main fatty acids followed by linoleic acid in Crimson Sweet watermelon, respectively. Moreover, the ratio of polyunsaturated fatty acid to saturated fatty acids was determined as $1.16,1.20,1.27$ (room temperature, $4^{\circ} \mathrm{C}$, and newly harvested, respectively) which are in the desirable range for qualified oil.
\end{abstract}

Keywords: Crimson Sweet watermelon, fatty acids, Omega 6, temperature

\footnotetext{
${ }^{1}$ Mozhgan ZARIFIKHOSROSHAHI (Orcid ID: 0000-0001-5491-1430), Cukurova University, Faculty of Agriculture, Department of Horticulture, Adana, Turkey

${ }^{2}$ Zeynep ERGUN (Orcid ID: 0000-0002-9868-9488), Adana Alparslan Turkes Science and Technology University, Faculty of Engineering, Department of Bioengineering, Adana, Turkey

*Corresponding Author: Mozhgan ZARIFIKHOSROSHAHI, e-mail: mn_zarifi@yahoo.com
} 


\section{INTRODUCTION}

Increased global nutritional demands make the use of vegetable oils necessary for utilization in both food and industrial purposes such as cosmetics and soap making (Nwosu et al., 2017). Oil extracted from some seeds, cereal grains, nuts and fruits such as watermelon and melon are known as vegetable oils. However, some vegetable oils are not produced in commercial quantities. Citrullus lanatus (watermelon) is a member of Cucurbitaceae, a family also referred to as cucurbits which has around 800 species and 130 genera (Najafi et al., 2010). Melons, pumpkins, squashes, and gourds are also the member of this family. Due to sweet flavor and high nutritional value, watermelon is mainly consumed as a fruit widely in some regions of the world, mainly in Africa and Asia. Besides consuming as a source of nutrition, it is also used in folk medicine for the treatment of strangury (Ziyada and Elhussien, 2008). Watermelon as a tropical plant requires a lot of sunshine and a high temperature of over $25^{\circ} \mathrm{C}$ for optimum growth. Drained fertile soil with a moderately acidic nature is a favorite condition for watermelon to grow up (Tabiri et al., 2016). Watermelons have important nutrition value because of rich vitamins $\mathrm{B}, \mathrm{C}$, and $\mathrm{E}$ and $\beta$-carotene sources and also contain considerably large amounts of lycopene (Choudhury et al., 2015). Watermelon bioactive content especially lycopene contributes to quenching the free radicals causing diseases such as atherosclerosis, asthma, colon cancer, diabetes, and arthritis. Moreover, watermelon contains high levels of fibers and citrulline, the precursor of arginine amino acid (Tabiri et al., 2016). The quality of watermelon varieties is extremely based on the sugar content and its sweetness. Watermelon can be used as fresh salad, dessert, snacks, and decorations. Besides consuming watermelon fruit flesh, its seeds also are highly nutritional. Watermelon seeds are rich sources of minerals (such as magnesium, potassium, phosphorus, sodium, iron, calcium, zinc, manganese, and copper), vitamins B, protein (31.9\%), and fat (57.1\%) (Braide et al., 2012). Some nations consume watermelon seed oil in the cooking and manufacturing of cosmetics but not on an industrial scale (Jensen et al., 2011). Watermelon seeds also contain Leucine, Isoleucine, Tryptophan, and Valine necessary amino acids (Razavi and Milani, 2006). Watermelon seed oils have been studied in different parts of the world because it has a high content of linoleic acid (Ziyada and Elhussien 2008, Taiwo et al., 2008). Despite the different potential applications and nutrition value, the watermelon seeds are often discarded while the fruit is eaten. The recovery and use of agricultural and food processing by-products lead to a decrease in waste disposal problems besides increased limited resources (Kamel et al., 1985). Recently by increasing the demand of the growing population for vegetable oil, the researchers have focused on the exploring of potential and newer plant resources for oil production at an industrial scale (Anhwange, 2004, Parry et al., 2005; Ramadan et al., 2006; Mabaleha et al., 2007; Celik and Ercisli, 2009; Nehdi, 2011). Moreover, investigation on postharvest conditions and periods on changes in wanted characteristics is an important issue in the evaluation of new seed oil sources. On the other hand, fatty acid composition is affected by temperature during seed maturation (Canvin, 1965). Whereas the production of saturated fatty acids increases in warm, dry growing conditions, cooler, moist conditions lead to the production of the polyunsaturated fatty acids (Harris et al., 1978; Yaniv et al., 1995).

In this study, it was aimed to determine the fatty acid profile of Crimson sweet watermelon oilbearing seeds with high nutritional importance storing at different temperatures to compare with newly harvested ones. Therefore, the old seeds can be evaluated in oil production. 


\section{MATERIALS AND METHODS}

\section{Plant Material}

Citrullus lanatus var. lanatus were used in this study. The seeds were provided by a commercial company (Haluk Gebzeli-Gebzeli Ziraat). The samples were treated at room temperature and $+4^{\circ} \mathrm{C}$ (in conservation refrigerator) for 12 months and compared with newly harvested seeds. Seeds in-room temperatures were kept in special seed storage rooms with adjusted temperature $\left(25^{\circ} \mathrm{C}\right)$, darkness, and humidity $(\% 20)$.

\section{Oil Extraction}

The oils of all samples were extracted at the same time (immediately after harvest of new samples, the conserved seeds and newly harvested ones were used). Obtained fresh oil was analyzed for fatty acids via an automatic soxhlet device (Gerhardt GmbH \& Co. KG). Nine grams of dried seed and tuber samples were used for oil extraction. Hexane (Merck KGaA, Darmstadt, Germany) was used as a solvent and extracted oil was weighted for determination of the oil percent in the samples. The oil content of seeds and tubers were expressed as $\mathrm{g}_{100 \mathrm{~g}^{-1}}$ of dry samples. Esterification of fatty acids was done based on David et al., (2003) method.

\section{Determination of Fatty Acids}

The fatty acids were analyzed by a GC (Perkin Elmer, Shelton, USA). Chromatographic separation was performed using a (30 $\mathrm{m} \times 0.25 \mathrm{~mm}$ ID, $0.25 \mu \mathrm{m}$ film thickness DB-Wax) column equipped with a flame ionization detector (FID). The oven temperature was $50^{\circ} \mathrm{C}$ for $1 \mathrm{~min}$, raised to $25^{\circ} \mathrm{C} \min ^{-1}$ to $200^{\circ} \mathrm{C}$, then $3^{\circ} \mathrm{C} \mathrm{min}^{-1}$ to $230^{\circ} \mathrm{C}$ which was held for $18 \mathrm{~min}$, while the injector and the detector temperatures were set at $280^{\circ} \mathrm{C}$ and $250^{\circ} \mathrm{C}$, respectively. The results were expressed in $\mathrm{GC}$ area $\%$ as a mean value and \pm standard deviation (David et al., 2003).

\section{Statistical Analysis}

The statistics of biochemical analysis were done using JMP statistical software from SAS (Version 7). Differences among the mean values were detected by the least significant differences (LSD) test at a $5 \%$ level. The fatty acid analysis was employed two times for each oil sample.

\section{RESULTS AND DISCUSSION}

The fatty acid composition of seed oils of Crimson Sweet at different storage conditions is shown in Table I. The results showed that linoleic acid, palmitic acid, oleic acid, and stearic acids are the main fatty acids in Crimson Sweet watermelon, respectively. Linoleic acid, the omega-6 fatty acid, is known as an essential fatty acid because the human body cannot synthesize it.

Therefore, Crimson Sweet watermelon seed oils are extremely nutritious oils to reduce serum cholesterol and remedy cardiovascular disorders (Nicolosi et al., 2004, Manzoor et al., 2007). In terms of total oil percentage, the seeds which were stored at $4^{\circ} \mathrm{C}$ had a high amount of total oil $(26.05 \%)$ compared to others. While the oil contents of seeds in the present study were found to be lower than those reported by Mogotlane et al., (2018) (30-41.5\%) from different indigenous C. lanatus seeds (30$41.5 \%$ ), the obtained results are confirmed by the findings of Tabiri et al., (2016) (Charleston gray 26.83\%, Crimson Sweet 26.50\%, and Black diamond 27.83\%). On the other hand, Al-Khalifa (1996) reported that C.lanatus seed oils from Iran, Egypt, and China (20,24, and 21\%, respectively) were lower than Crimson Sweet watermelon studied in this study. Crimson Sweet watermelon had a high amount of total poly saturated fatty acids comprising $\alpha$-Linolenic acid and Linoleic acid. While no significant differences were obtained between newly harvested watermelon seeds $(42.34 \%)$ and the seeds stored at $4^{\circ} \mathrm{C}(42.19 \%)$, the seeds stored at room temperature showed lower content $(40.62 \%)$ of PUFA. Thirteen 
saturated fatty acids were detected at Crimson Sweet watermelon in this study which the main ones were palmitic acid and stearic acid. The amount of total SFA was high following the total PUFA. In contrast to total PUFA, newly harvested seeds had lower (33.27\%) saturated fatty acids. The seeds stored at room temperature had high levels of palmitic acid (19.17\%) and stearic acid (13.86\%) (SFAs) (Fig. 2). Whereas the amount of oleic acid as monosaturated fatty acid was higher in newly harvested seeds (17.29\%) (Fig. 3), there were no significant differences between seeds stored at $4^{\circ} \mathrm{C}$ (16.36\%) (Fig. 1) and room temperature (16.35\%) (Fig. 2). The amount of total saturated fatty acids in the present study are comparable with those reported (64.6-88.2\%) for different species of muskmelon (Tilak et al., 2006). The differences among studies may be due to different cultivar and genotypes used along with different oil extraction methods. As the results reveal, newly harvested samples and the ones stored at $4^{\circ} \mathrm{C}$ had higher PUFA while the amount of PUFA has decreased and may be converted to SFA at samples that are stored at room temperature. However, the ratio of PUFA: SFA is the highest at newly harvested samples (1.27) followed by seeds stored at $4^{\circ} \mathrm{C}(1.20)$. Consequently, the storage conditions may influence the fatty acid composition of seed oils. Although there is no evidence of storage temperature effect on the conversion of PUFA to SFA, researchers reported that dry and warm conditions are favor for SFA to be produced while moist and cooler conditions are favor to PUFA to be produced (Harris et al., 1978; Yaniv et al., 1995).

Table I - The fatty acid composition of seed oils of Crimson Sweet at different storage conditions [\%]

\begin{tabular}{|c|c|c|c|c|}
\hline Fatty Acids & Room temperature & $4^{\circ} \mathrm{C}$ & new harvest & LSD \\
\hline Oil Percent & 25.21 & 26.05 & 25.56 & - \\
\hline Myristic Acid (C14:0) & $0.11 \pm 0.02$ & $0.95 \pm 0.004$ & $0.11 \pm 0.002$ & N.S \\
\hline Palmitic acid (C16:0) & $19.17 \pm 0.11^{\mathrm{a}}$ & $18.86 \pm 0.11^{\mathrm{a}}$ & $18.31 \pm 110^{\mathrm{b}}$ & $0.523^{*}$ \\
\hline Stearic acid (C18:0) & $13.86 \pm 0.01^{\mathrm{a}}$ & $13.50 \pm 0.10^{\mathrm{b}}$ & $13.09 \pm 0.10^{\mathrm{c}}$ & $0.343^{*}$ \\
\hline Arachidic acid (C20:0) & $0.58 \pm 0.004^{\mathrm{a}}$ & $0.55 \pm 0.004^{\mathrm{b}}$ & $0.55 \pm 0.004^{\mathrm{b}}$ & $0.018^{*}$ \\
\hline Caprylic acid (C8:0) & $0.34 \pm 0.007^{\mathrm{b}}$ & $0.38 \pm 0.014^{\mathrm{a}}$ & $0.35 \pm 0.012^{\mathrm{b}}$ & $0.029^{*}$ \\
\hline Capric acid (C10:0) & $0.05 \pm 0.000^{\mathrm{a}}$ & $0.04 \pm 0.001^{\mathrm{a}}$ & $0.03 \pm 0.001^{\mathrm{b}}$ & $0.013^{*}$ \\
\hline Behenic acid (C22:0) & $0.14 \pm 0.007^{\mathrm{a}}$ & $0.13 \pm 0.005^{\mathrm{ab}}$ & $0.12 \pm 0.004^{\mathrm{b}}$ & $0.018^{*}$ \\
\hline Caproic acid (C6:0) & $0.33 \pm 0.014^{\mathrm{c}}$ & $0.34 \pm 0.012^{\mathrm{a}}$ & $0.30 \pm 0.010^{\mathrm{b}}$ & $0.018^{*}$ \\
\hline Tricosanoic acid (C23:0) & $0.03 \pm 0.001^{\mathrm{a}}$ & $0.03 \pm 0.001^{\mathrm{a}}$ & $0.00 \pm 0.000^{\mathrm{b}}$ & $0.028^{*}$ \\
\hline Lignoseric acid (C24:0) & $0.13 \pm 0.005$ & $0.12 \pm 0.004$ & $0.12 \pm 0.004$ & N.S \\
\hline Undecanoic acid (C11:0) & $0.07 \pm 0.002$ & $0.07 \pm 0.003$ & $0.06 \pm 0.002$ & N.S \\
\hline Margaric Acid (C17:0) & $0.22 \pm 0.008^{\mathrm{a}}$ & $0.20 \pm 0.007^{\mathrm{ab}}$ & $0.19 \pm 0.007^{\mathrm{b}}$ & $0.018^{*}$ \\
\hline Pentadecanoic acid (C15:0) & $0.06 \pm 0.002$ & $0.04 \pm 0.002$ & $0.04 \pm 0.001$ & N.S \\
\hline$\Sigma$ SFA & 35.04 & 35.21 & 33.27 & \\
\hline Palmitoleic acid (C16.1) $\omega-7$ & $0.06 \pm 0.002$ & $0.07 \pm 0.002$ & $0.06 \pm 0.002$ & N.S \\
\hline Oleic acid $(\mathrm{C} 18: \ln 9 \mathrm{c}) \omega^{-9}$ & $16.35 \pm 0.12^{\mathrm{b}}$ & $16.36 \pm 0.12^{\mathrm{b}}$ & $17.29 \pm 0.13^{\mathrm{a}}$ & $0.815^{*}$ \\
\hline Eicosenoic acid $(\mathrm{C} 20: \ln 9 \mathrm{c}) \omega^{-9}$ & $0.08 \pm 0.003$ & $0.08 \pm 0.003$ & $0.08 \pm 0.003$ & N.S \\
\hline$\Sigma$ MUFA & 16.49 & 16.51 & 17.43 & \\
\hline a-Linolenik acid (C18:3n3) $\omega^{-3}$ & $0.11 \pm 0.004^{\mathrm{b}}$ & $0.12 \pm 0.004^{\mathrm{a}}$ & $0.11 \pm 0.004^{\mathrm{b}}$ & 0 \\
\hline Linoleic acid (Cl 8:2n6c) $\omega^{-6}$ & $40.62 \pm 0.30^{\mathrm{b}}$ & $42.19 \pm 0.32^{\mathrm{a}}$ & $42.34 \pm 0.31^{\mathrm{a}}$ & $1.046^{*}$ \\
\hline $\begin{array}{c}\Sigma \text { PUFA } \\
\end{array}$ & 40.73 & 42.31 & 42.45 & \\
\hline
\end{tabular}

*LSD. Least Significant Difference (LSD). *N.S: No significant differences. SFA: Saturated Fatty acid; MUFA:

Monounsaturated fatty acid; PUFA: Polyunsaturated Fatty acid. 


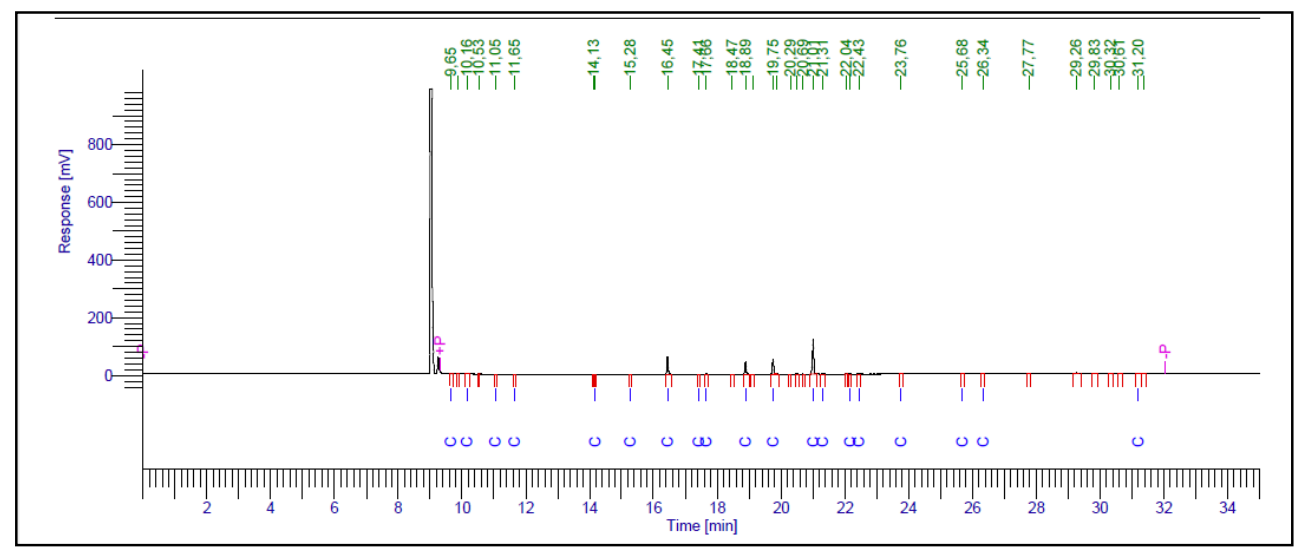

Figure 1 - The chromatogram of fatty acids of Crimson watermelon seeds at $4^{\circ} \mathrm{C}$

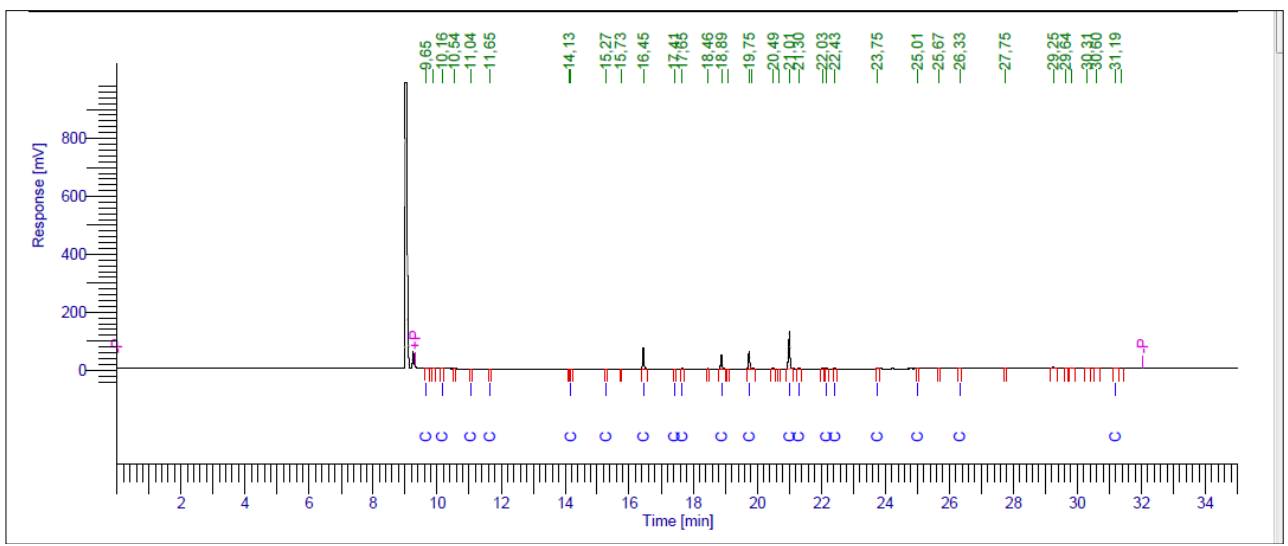

Figure 2 - The chromatogram of fatty acids of Crimson watermelon seeds at room temperature

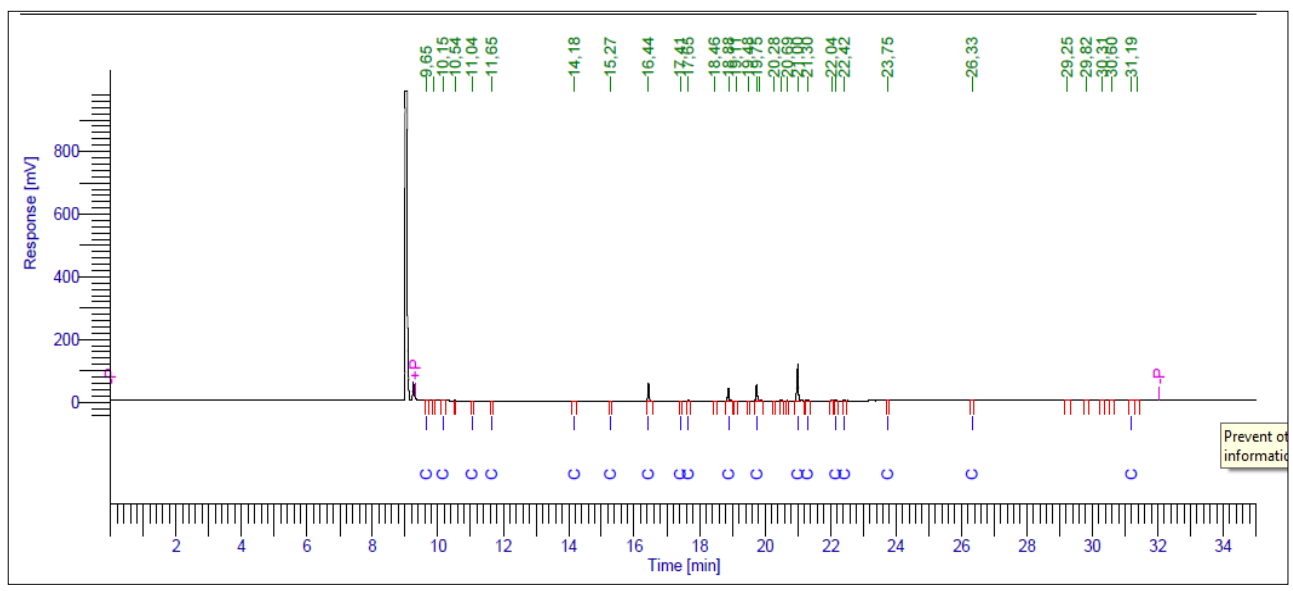

Figure 3 - The chromatogram of fatty acids of newly harvested seeds of Crimson watermelon

\section{CONCLUSION}

The results of this study proved that the seeds of Crimson sweet watermelon are a good source of high omega 6 fatty acid. Therefore, seed oil can be evaluated as a highly notorious and healthy source in the human diet. Although the results showed that the seeds which are newly harvested and the seeds stored at cool places have a high amount of PUFA, the seeds stored at room temperature also have adequate PUFA to be evaluated at oil extraction and uses. By all, the results showed that storage temperature may affect the fatty acid composition but no matter the storage conditions, the seeds may be used for oil extraction at an industrial scale. 
The Effect of Storage Temperature on the Composition of Fatty Acids in Crimson Sweet (Citrullus lanatus var. lanatus) Watermelon Cultivar Seeds

\section{Conflict of Interest}

The authors declare that they have no conflict of interest.

\section{Author's Contiibutions}

The authors contributed equally to this manuscript. The authors contributed to the discussion of the results and all of them read and approved the final manuscript.

\section{REFERENCES}

Al-Khalifa AS, 1996. Physicochemical characteristics, fatty acid composition, and lipoxygenase activity of crude pumpkin and melon seed oils. Journal of Agricultural and Food Chemistry 44 (4): 964-966.

Anhwange BA, Ajibola VO, Oniye SJ, 2004. Chemical studies of the seeds of Moringa oleifera (Lam) and Detarium microcarpum (Guill and Sperr). J. Biol. Sci. 4 (6): 711-715.

Braide W, Odiong IJ, and Oranusi S, 2012. Phytochemical and Antibacterial properties of the seed of watermelon (Citrullus lanatus). Prime Journal of Microbiology Research 2 (3): 99-104.

Canvin DT, 1965. The effect of temperature on the oil contenit and fatty acid composition of the oils from several oil seed crops. Cani. J. Botany 43: 63-69.

Celik F, and Ercisli S, 2009. Lipid and fatty acid composition of wild and cultivated red raspberry fruits (Rubus idaeus L.). J. Med. Plants Res. 3: 583-585.

Choudhury BR, Haldhar SM, Maheshwari SK, Bhargava R, Sharma SK, 2015. Phytochemicals and antioxidants in watermelon (Citrullus lanatus) genotypes under hot arid region. Indian Journal of Agricultural Sciences 85 (3): 414-417.

David F, Sandra P, Wylie P, 2003. Improving the Analysis of Fatty Acid Methyl Esters Using Retention Time Locked Method and Retention Time Databases," Application Note 5990-4822EN, Agilent Technologies publication 5988-5871EN.

Harris HC, McWilliam JR, and Masson WK, 1978. Influence of temperature on oil content and composition of sunflower seed. Aust. J. Agric. Res. 29: 1203-1212.

Jensen BD, Toure FM, Hamattal MA, Toure FA, and Nantoumé DA, 2011. Watermelons in the Sand of Sahara: Cultivation and use of indigenous landraces in the Tombouctou Region of Mali. Ethnobotany Research and Applications 9: 151-162.

Kamel BS, Dawson H, and Kakuda Y, 1985. Characteristics and composition of melon and grape seed oils and cakes. Journal of the American Oil Chemists' Society 62 (5): 881-883.

Mabaleha MB, Mitei YC, Yeboah SO, 2007. A comparative study of the properties of selected melon seed oils as potential candidates for development into commercial edible vegetable oils. J. Am. Oil Chem. Soc. 84: 31 36.

Manzoor MF, Anwar T, Iqbal M, Bhanger I, 2007. Physicochemical characterization of Moringa concanensis seed and seed oil. Journal of American Oil Chemist Society, 84: 413-419.

Mogotlane EA, Mokwala PW, Mangena P, (2018). Comparative analysis of the chemical compositions of indigenous watermelon (Citrullus lanatus) seeds from two districts in Limpopo Province, South Africa. African Journal of Biotechnology, 17(32), 1001-1006.

Najafi S, Sanadgol N, Nejad B. S, Beiragi M. A, Sanadgol, E. (2010). Phytochemical screening and antibacterial activity of Citrullus colocynthis (Linn.) Schrad against Staphylococcus aureus. Journal of Medical Plants Research 4 (22): 2321-2325.

Nehdi IA, 2011. Characteristics and composition of Washingtonia filifera (Linden ex André) H. Wendl., seed and seed oil. Food Chem. 126: 197-202.

Nicolosi RJ, Woolfrey B, Wilson TA, Scollin P, Handelman G, Fisher R, 2004. Decreased aortic early atherosclerosis and associated risk factors in hypercholesterolemic hamsters fed a high- or midoleic acid oil compared to a high-linoleic acid oil. Journal of Nut. Biochem. 15: 540-547. 
Nwosu C, Ozumba IC, Kabir AO, 2017. Effect of Process Parameters on the Physical Properties of Watermelon Seed Oil under Uniaxial Compression. Nutri Food Sci Int J. 4(1): 555626.

Parry J, Su L, Luther M, Zhou K, Yurawecz MP, Whittaker P, Yu L, 2005. Fatty acid composition and antioxidant properties of cold-pressed marionberry, boysenberry, red raspberry, and blueberry seed oils. J. Agric. Food Chem. 53: 566-573.

Ramadan MF, Sharanabasappa G, Parmjyothi S, Seshagiri M, Moersel JT, 2006. Profile and levels of fatty acids and bioactive constituents in mahua butter from fruit-seeds of buttercup tree [Madhuca longifolia (Koenig)]. Eur. Food Res. Technol. 222: 710-718.

Razavi SM, Milani E, 2006. Some physical properties of the watermelon seeds. African Journal of Agricultural Research 1 (3): 065-069.

Tabiri B, Agbenorhevi JK, Wireko-Manu FD, Ompouma EI, 2016. Watermelon seeds as food: Nutrient composition, phytochemicals and antioxidant activity.

Taiwo AA, Agbotoba MO, Oyedepo JA, Shobo OA, Oluwadare I, Olawunmi MO, 2008. Effects of drying methods on properties of water melon (Citrullus lanatus) seed oil. Afr. J. Food Agr. Nutr. Dev. 8: 16845374.

Tilak RM, Tukaram A, Brij ML, Valangaman SS, 2006. A study of seeds of musk melon (Cucumis melo L.), A lesser known source of edible oil. J. Sci. Food Agri. 10: 973-978.

Yaniv Z, Schafferman D, Zur M, 1995. The effect of temperature on oil quality and yield parameters of high-and low-erucic acid Cruciferae seeds (rape and mustard). Industrial Crops and Products 3 (4): 247-251.

Ziyada AK, Elhussien SA, 2008. Physical and chemical characteristics of Citrullus lanatus var. colocynthoide seed oil. J Phys Sci 19: 69-75. 